ISSN: 2581-8341

Volume 03 Issue 12 December 2020

DOI: 10.47191/ijcsrr/V3-i12-03, Impact Factor: 6.595

IJCSRR@ 2020

www.ijcsrr.org

\title{
Surgical Management of Necrotizing Sialometaplasia of Hard Palate: A Case Report
}

\author{
Afroze Karishma ${ }^{1}$, Indu Palanivel ${ }^{2},{\text { Saravanan } \text { Chandran }^{3} \text {, Karthik Ramakrishnan }}^{4}$, Vivek Narayanan ${ }^{5}$ \\ ${ }^{1}$ Intern, BDS \\ ${ }^{2}$ Lecturer, MDS \\ ${ }^{3}$ Professor, FDSRCS \\ ${ }^{4}$ Professor, MDS \\ ${ }^{5}$ Professor; Head \& Dean, MDS
}

\begin{abstract}
Necrotizing Sialometaplasia is rare and in the oral cavity it accounts $<1 \%$ of all biopsied lesion. For decades Necrotizing Sialometaplasia were treated by conservative management as it is a self healing lesion. The progressive healing period was reported from 2 weeks to 3 months in the literature. Is necrotizing sialometaplasia a self-limiting disease? Here we report a case of nonhealing necrotizing sialometaplasia which was treated by surgical management. Complete regression of the lesion was evident after the surgical management and no recurrence until two years of follow-up.
\end{abstract}

Keywords: Necrotizing Sialometaplasia, palate, self-limiting disease

\section{INTRODUCTION}

Necrotizing Sialometaplasia (NS) is rare and in the oral cavity it accounts $<1 \%$ of all biopsied lesion [1]. 80\% of NSM involves minor salivary glands of palate. Other sites of involvement are floor of mouth, trachea, tongue, nasal cavity, retromolar, maxillary sinus, tonsil, larynx and major salivary glands [2].

The etiopathogenesis of NS is unclear, however, it is suggested that vascular insufficiency to the salivary gland lobule is the major cause. Apart from ischemia other etiologies were related to infections, physical andchemical trauma. Physical trauma includes local anesthetic injections, dental appliances, intubation, previous surgeries and direct forceful traumatic injuries. Chemical trauma resulting from tobacco, bulimia, alcohol and other gastro-esophageal reflex were the other possibilities. In the infectious etiology respiratory tract infections and viral etiology have been reported [3].

The known statement "NS is a self healing or self limiting lesion."For decades conservative management with symptomatic treatment such as topical corticosteroids, non-steroidal anti-inflammatory drugs were the treatment of choice as a less invasive procedure for NS [4,5]. In the literature the progressive healing period is reported from 2 weeks to 3 months [6]. Is necrotizing sialometaplasia a self-limiting disease? Here we report a case of non-healing necrotizing sialometaplasia which was treated by surgical management.

\section{CASE REPORT}

A 52 years old male patient presented with a complaint of pain and ulcer over the right hard palatefor past one month. No associated findings with regard to previous medical and surgical history. Patient's dental historyrevealedextraction of tooth (14 and 15) at outside hospital before one month. Patient consulted same dentist one week after extraction for an erythema which developed in the area of palatal anestheticinjection. Patient was advised antibiotics for the same but no improvement in the symptom. After 3 weeks patient noticed an ulcerwhich was slowly increasing to attain the size of $0.3 \times 0.3 \mathrm{~cm}$ and patient reported to our institution [Figure 1]. Examination revealed no enlargement of lymph node. Salivary flow from major salivary gland ducts was normal thus no evidence of clinical obstruction. OPG and IOPA revealed no evidence of radiolucency, no bone loss and no other foci of infection. Patient was started on intra lesional injection of triamcinolone $10 \mathrm{mg}$, once in a two weeks which was continuedfor three weeks. Erythema in the surrounding mucosa was resolving but no signs of healing in the ulcer. Two weeks after the supportive treatment when the patient was called for review, it appeared as a crater-like ulceration of size $1.5 \times 1.5 \mathrm{~cm}$, oval in shape with the exposure of necrotic tissue at the center, well defined borders, no bleeding and no exposure of bone [Figure 2]. CT scan was done which revealed no bony erosion or maxillary sinus opacification. Patient was admitted and surgical excision was done under General Anesthesia. 


\section{International Journal of Current Science Research and Review}

ISSN: 2581-8341

Volume 03 Issue 12 December 2020

DOI: 10.47191/ijcsrr/V3-i12-03, Impact Factor: 6.595

IJCSRR@ 2020

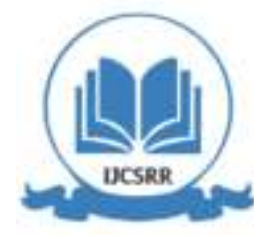

WWw.ijcsrr.org

Palatal plate was given post-operatively. Complete regression of the lesion is evident 1 month after the excision [Figure 3]. No recurrence until two years of follow-up.

\section{DISCUSSION}

Necrotizing sialometaplasia was first delineated by Albert Abrams as a disease which stimulates malignancy in 1973 [7]. NS resembles Squamous Cell Carcinoma and Mucoepidermoid carcinoma therefore it should not be bemused as malignant condition. Histological similarity of these conditions is due to the presence of pseudo-epitheliomatous hyperplastic epithelium [8]. The key discriminating features of NS from squamous cell carcinoma are lobular architecture preservation, inflammatory infiltrate and lobular infraction. Presence of mucin pools, glandular lumina in metaplastic nest and bland squamous cell appearance are the other discriminating features [9]. The distinguishing feature of NS from Mucoepidermoid carcinoma is the absence of cystic space which is lined by mucous cells [10]. Proper diagnosis should be made with clinical history and histologic correlation to evadeunnecessary aggressive surgical treatment.

NS is treated conservatively since few decades as it is a self limiting lesion and it heals spontaneously with or without supportive treatment [11], [12]. Healing period is reported from 4 to 10 weeks without specific treatment [13]. Sun Ah Shin et al [14] recommended conservative management for palatal NS in young adults to avoid aggressive surgery. Tanu Randhawa et al [15] reported NS of tongue and the report concluded that NS does not require specific treatment. Although NS was treated conservatively, few literatures reported surgical management [16].

In our case, the ulcer was not resolved even after three months. Clinical differential diagnosisas malignant ulcer was considered. Patientunderwent surgical debridement under General Anesthesia. Histopathological diagnosis of NS was made. After 2 weeks of surgical management, healing of the lesion occurred eventually. The hypothesis behind this non- resolving NS for more than three months is unclear. This type of non-resolving NS should not be confused with malignant conditions.

In the literature to our knowledge this is the first case of non resolving NS which was treated surgically. Though rare, it is important to establish the etiological theories behind NS. Further clinical studies and etiopathological theories should be encouraged to avoid perplexity in diagnosis and management of Necrotizing Metaplasia.

\section{REFERENCES}

1. Kandula S, Manjunatha BS, Tayee P, Astekar M. Bilateral necrotizing sialometaplasia. BMJ Case 2016:bcr2015211348. doi: 10.1136/bcr-2015-211348.

2. Ashwarya Trivedi, Mysore K Sunil, Sonam Gupta, Shaveta Garg. Necrotizing sialometaplasia of the palate: A case report. Journal of Indian Academy of Oral Medicine \& Radiology 2014; 26: 355-358.

3. Ilana Kapla, Michael Alterman, Shlomo Kleinman, Vadim Reiser, Amir Shuster, Yaniv Dagan, Benjamin Shlomi. The clinical, histologic, and treatment spectrum in necrotizing Sialometaplasia. Oral Surg Oral Med Oral Pathol Oral Radiol2012; 114:577-585.

4. Alessandro Gatti, Emanuele Broccardo, Giuseppe Poglio, Arnaldo Benech. Necrotizing Sialometaplasia of the Hard Palate in a Patient Treated with Topical Non-steroidal Anti Inflammatory Drug. Case Reports in Dentistry 2016, Article ID 9545861, http://dx.doi.org/10.1155/2016/9545861

5. BenguCobanoglu, Selcuk Arslan, Ismail Saygin.A rare case of necrotizing sialometaplasia of palate treated with intralesional steroid injection. Journal mucosa 2018; 1: 24-27.

6. Diane L. Carlson. Necrotizing Sialometaplasia: A Practical Approach to the Diagnosis. Arch Pathol Lab Med. 2009; 133:692-698.

7. Abrams A M, Melrose R J, Howell, F. V. Necrotizing sialometaplasia. A disease simulating malignancy. Cancer 1973; 32: 130-135. doi:10.1002/1097-0142(197307)32:1<130::aid-cncr2820320118>3.0.co;2-8

8. Mesa ML, Gertler RS, Schneider LC. Necrotizing sialometaplasia: Frequency of histologic misdiagnosis. Oral Surgery, Oral Medicine, Oral Pathology 1984; 57: 71-73. doi:10.1016/0030-4220(84)90264-0

9. Diane L. Carlson. Necrotizing Sialometaplasia: A Practical Approach to the Diagnosis. Arch Pathol Lab Med. 2009; 133:692-698.

10. Gnepp DR, Brandwein MS, Henley JD. Salivary and lacrimal glands. In: GneppDR,ed. Diagnostic surgical pathology of the head and neck. 2nd edn. Philadelphia: Saunders, 2009:325-430. 


\section{International Journal of Current Science Research and Review}

ISSN: 2581-8341

Volume 03 Issue 12 December 2020

DOI: 10.47191/ijesrr/V3-i12-03, Impact Factor: 6.595

IJCSRR@ 2020

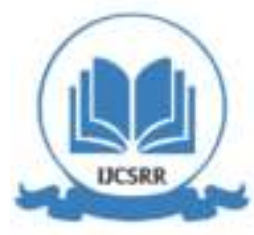

Www.ijcsrr.org

11. Luna E B, Janini M E R, Meirelles V, Werneck J T, Postorivo R, DE Rocha Curvello J A, Agostini M. Necrotizing Sialometaplasia of the Inferior Lip: Case Report and Conservative Management. Oral Surgery, Oral Medicine, Oral Pathology and Oral Radiology 2014; 117: e174. doi:10.1016/j.oooo.2013.12.13

12. Srinivas Kandula, Bhari Sharanesha Manjunatha, Priyanka Tayee, Madhusudan Astekar. Bilateral necrotisingsialometaplasia. BMJ Case Rep 2016. doi:10.1136/bcr-2015-211348

13. R. B. Brannon, C. B. Fowler, K. S. Hartman. Necrotizing sialometaplasia. A clinicopathologic study of sixty-nine cases and review of the literature. Oral Surgery, Oral Medicine, Oral Pathology 1991; 72: 317-325.

14. Sun Ah. Shin, Hee Young Na, Ji Young Choe, Seung-No Hong, Ho Lee, Sunwon Park, Ji Eun Kim. Necrotizing sialometaplasia: a malignant masquerade but questionable precancerous lesion, report of four cases. BMC Oral Health 2020; 20:206. https://doi.org/10.1186/s12903-020-01189-1

15. Tanu Randhawa, Ipe Varghese, PM Shameena, S Sudha, Resmi G Nair. Necrotizing sialometaplasia of tongue. J Oral MaxillofacPathol 2009; 1: 35-37. doi: 10.4103/0973-029X.48755

16. Balaji SM, Preetha Balaji. Surgical management of necrotizing sialometaplasia of palate. Indian Journal of Dental Research 2015; 26: 550-550.

\section{LIST OF FIGURES:}

Figure 1: Intraoral picture of an ulcerthree weeks after extraction measuring approximately $0.3 \times 0.3 \mathrm{~cm}$

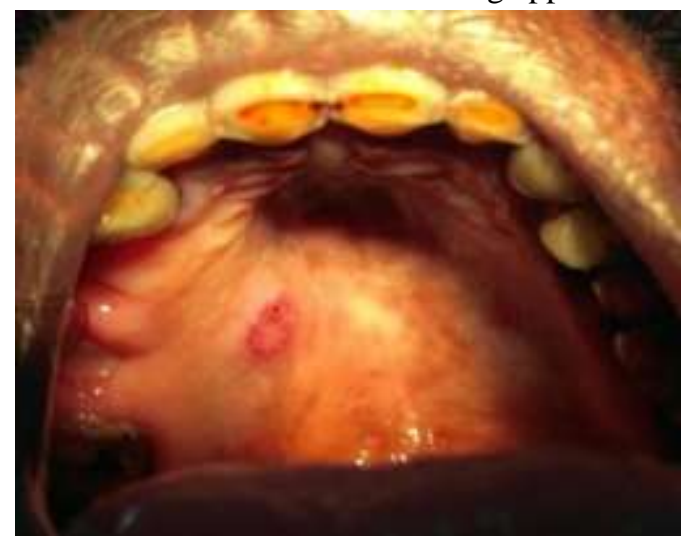

Figure 2: Clinical representation of ulcer at the end of $11^{\text {th }}$ week exposing necrotic tissue in the center ofcrater-like ulceration on the right hard palate.

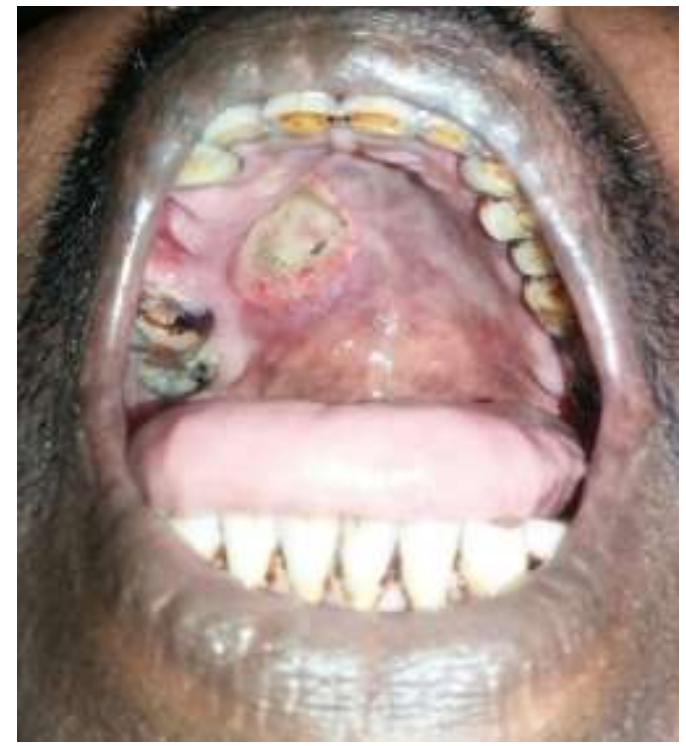




\section{International Journal of Current Science Research and Review}

ISSN: 2581-8341

Volume 03 Issue 12 December 2020

DOI: 10.47191/ijesrr/V3-i12-03, Impact Factor: 6.595

IJCSRR@ 2020

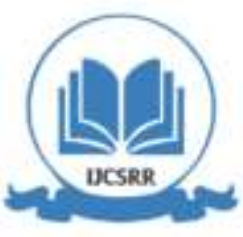

www.ijcsrr.org

Figure 3: Complete regression of an ulcer at one year follow up

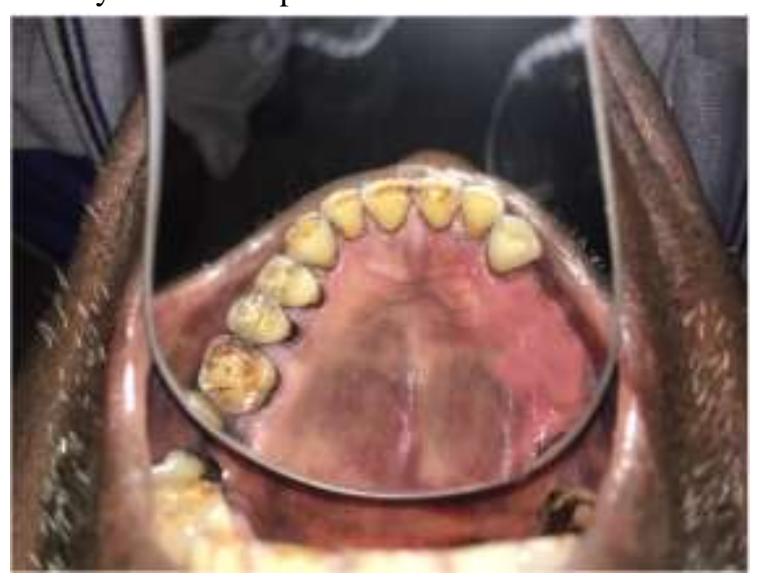

Cite this Article: Afroze Karishma, Indu Palanivel, Saravanan Chandran, Karthik Ramakrishnan, Vivek Narayanan (2020). Surgical Management of Necrotizing Sialometaplasia of Hard Palate: A Case Report. International Journal of Current Science Research and Review, 3(12), 213-216 